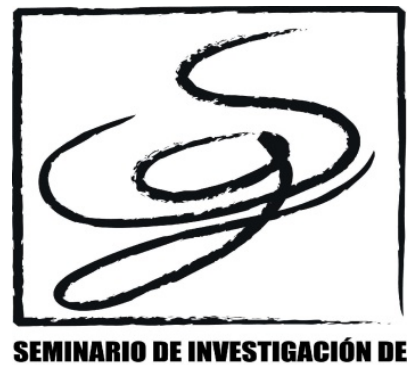

\title{
Personajes femeninos, padrotes y prostitución de menores en la novela Amorosos fantasmas de Paco Ignacio Taibo II
}

Female characters, padrotes and the prostitution of minors in the book Amorosos fantasmas by Paco Ignacio Taibo II

\section{Diego Ernesto Parra Sánchez \\ Universidad del País Vasco \\ dparra844@gmail.com}

Fecha de recepción: 18/06/2020 Fecha de evaluación: 30/09/2020

Fecha de aceptación: 16/11/2020

\begin{abstract}
:
Amorosos fantasmas is a novel written by Paco Ignacio Taibo II that belongs to the crime fiction genre and was published in 1989. The sixth installment of his most representative detective saga, the one starring the investigator Héctor Belascoarán Shayne, narrates the research about the murder of a young minor, named Virginia, after trying to escape from a criminal network, located in Mexico City and dedicated to the prostitution of minors, who, with the mediation of a pimp, tried to capture her. This work demonstrates that, as in all the Mexican author's detective narrative, in which the literary formula is always oriented towards political and social denunciation, the novel exudes almost every page disenchantment and frustration at the social injustice and exploitation of more disadvantaged citizens and exposed to the excesses of the corrupt PRI system. In this case, the corrosive denunciation of Taibo II focuses on topics such as violence against women and female sexual exploitation in the urban environment through, first of all, the most relevant female characters in the novel: the victims Virginia and Laura. And, secondly, the analysis of a social archetype deeply rooted in Mexico: that of the pimp, embodied by the character of Manuel. Dedicated to the recruitment of sex servants, in many cases minors, and to the intermediation between them and the client, the novel uncovers the gears of this lucrative system of abuse and domination. Furthermore, in doing so, he is right to portray it as a network in which, although the pimp plays an axial role, there is a collective structure similar to that of a criminal organization that protects the pimp and benefits from his actions.
\end{abstract}


Key words: Paco Ignacio Taibo II; detective fiction; woman; violence; padrote; prostitution; disenchantment; social criticism

\section{Resumen:}

Amorosos fantasmas es una novela escrita por Paco Ignacio Taibo II que pertenece al género policíaco y que fue publicada en el año 1989. La sexta entrega de su saga detectivesca más representativa, la protagonizada por el investigador Héctor Belascoarán Shayne, narra la pesquisa en torno al asesinato de una joven menor de edad, llamada Virginia, después de intentar escapar de un entramado criminal, ubicado en la Ciudad de México y dedicado a la prostitución de menores, que, con la mediación de un padrote, la pretendía captar. Este trabajo demuestra que, como en toda la narrativa policíaca del autor mexicano, en la que la fórmula literaria está siempre orientada hacia la denuncia política y social, la novela destila casi a cada página desencanto y frustración ante la injusticia social y la explotación de los ciudadanos más desfavorecidos y expuestos a los excesos del corrupto sistema prí́sta. En este caso, la corrosiva denuncia de Taibo II focaliza sobre temas como la violencia hacia la mujer y la explotación sexual femenina en el entorno urbano a través, en primer lugar, de los personajes femeninos más relevantes de la novela: las víctimas Virginia y Laura. Y, en segundo lugar, del análisis de un arquetipo social de gran arraigo en México: el del padrote, encarnado por el personaje de Manuel. Dedicado a la captación de sexo servidoras, en muchas ocasiones menores de edad, y a la intermediación entre estas y el cliente, la novela destapa los engranajes de este lucrativo sistema de abuso y dominación. Además, al hacerlo, acierta al retratarlo como un entramado en el que, aunque el padrote juega un papel axial, existe una estructura colectiva semejante a las de una organización criminal que ampara al padrote y se beneficia de sus acciones.

Palabras clave: Paco Ignacio Taibo II; ficción detectivesca; mujer; violencia; padrote; prostitución; desencanto; crítica social

\section{Introducción a la narrativa de Paco Ignacio Taibo II}

Nacido en Gijón en 1949 pero afincado en la Ciudad de México desde 1959, Paco Ignacio Taibo II es uno de los autores internacionalmente más reconocidos en el área de la literatura policíaca.

Siempre comprometido con la realidad social a pie de calle, a lo largo de su trayectoria profesional ha desempeñado labores muy diversas que van desde la política, el activismo sindical o la docencia universitaria, al periodismo o la creación tanto de certámenes, como de organizaciones dedicadas al cultivo y el fomento de la literatura y la cultura en general. Las respectivas fundaciones de la Asociación Internacional de Escritores Policíacos en La Habana en 1986 y la Semana Negra de Gijón en 1988 son ejemplos claros de ello (Nichols, 1998: 230). 
Uno de los acontecimientos que más le marcaron como escritor y que, sin duda, terminó de perfilar su carácter contestatario y comprometido fue la revolución estudiantil de 1968 y su violenta represión, con la toma por la fuerza de la plaza de Tlatelolco el 2 de octubre de ese mismo año por la policía estatal. Este está presente en su obra desde la publicación de su primer título, Nacimiento de la memoria (1971), trabajo en el que reflexiona sobre los acontecimientos más relevantes de la historia reciente de México por medio de una narración a caballo entre el ensayo y la crónica histórica.

\begin{abstract}
Después de todo, solo había sido un movimiento estudiantil de 123 días de duración. Nada más. Nada menos. Pero nos había dado, a una generación completa de estudiantes, pasado y país, tierra debajo de los pies. (...) Nos dio este combustible de resistencia y terquedad que marcó al conjunto del movimiento, (...) una "noción de patria", óseamente encarnada (Taibo II, 1991: 114).
\end{abstract}

Si nos ceñimos a su labor como autor de literatura criminal, además de ser considerado como uno de los precursores de la nueva narrativa policíaca en Latinoamérica, junto con autores como el cubano Leonardo Padura o el argentino Mempo Giardinelli, y el acuñador del término neopolicial (Torres, 2003: 15), Taibo II es un autor prolijo. Al género tiene dedicadas varias novelas que han sido publicadas en veintinueve países y traducidas a una docena de idiomas. Su primera novela criminal es Días de combate, del año 1976. A esta le seguirá Cosa fácil, de 1977, en una exitosa confirmación editorial que consolida el nacimiento de una de las series detectivescas más relevantes de la literatura policíaca en México, la del detective Héctor Belascoarán Shayne. En un momento personal caracterizado por el desencanto, compartido por toda una generación, tras ver truncada la materialización de las reclamaciones que acompañaron las revoluciones populares de Mayo del 68, Taibo II encuentra en el relato policíaco el medio ideal con el que colmar la necesidad personal de practicar un tipo de literatura fuertemente arraigada en los problemas sociales del ciudadano a pie de calle y que se haga eco, a lo largo de sus páginas, de la cada vez más acuciante realidad mexicana:

Alrededor de 1974 caí en una época depresiva, a raíz de unos problemas personales, de una crisis en la vida política que llevaba, y entonces me replegué hacia mi vieja ambición de hacer literatura. [...] lo que quería hacer era una novela policíaca. Era la época del boom y todos querían escribir la gran novela que compitiera con La región más transparente, Conversación en la catedral y con las novelas de García Márquez. Descubrí que lo que deseaba escribir era una novela policíaca [porque] sabía que por su misma naturaleza, que por el hecho de plantear un problema criminal, traerla a México era apasionante, porque la 
criminalidad estaba frente a nosotros todos los días. Yo quería hacer una novela social y contar mis experiencias como náufrago del 68; y lo que más se acercaba [...] era la novela policiaca (Taibo II, 1999: 108-109).

El éxito de esta saga no tarda en llegar y, a comienzos de la década de los ochenta, comienza a intercalar narrativa criminal e historiografía. Una compaginación de trabajos y tipologías textuales que, desde ese momento, marcará su producción escritural, con una gran cantidad de títulos publicados hasta la fecha y con cuatro ejes temáticos fundamentales que, a partir de ese momento, destacarán como común denominador en todas ellas: en primer lugar, la activación de una reflexión crítica sobre el pasado y el presente de México; en segundo, la legitimación del concepto de revolución como herramienta necesaria para materializar cualquier deseo de transformación político-social frente al monopolio institucional del régimen priista; en tercer lugar, la proyección de una decidida reivindicación a favor, por un lado, de una clara y constatable regeneración política en clave progresista, y, por otro, de derechos ciudadanos como la igualdad y la justicia sociales; por último, la defensa de un posicionamiento sin dobleces al lado de las clases más desfavorecidas del régimen (como la inmigrante, la indígena o la obrera).

\section{Mujer y violencia en Amorosos fantasmas: una mirada a través del argumento y los personajes femeninos}

Si bien no está entre los temas más recurrentes de la narrativa criminal de Paco Ignacio Taibo II, dado que, en la mayoría de los casos el autor apunta a cuestiones de calado más político o económico como la corrupción gubernamental, la precariedad salarial o el abuso de autoridad policial, la mujer también se incluye dentro estas clases desfavorecidas e indefensas del entramado social retratado a través de sus novelas. Siempre ligada a nociones como violencia, abuso, inseguridad ciudadana y explotación mercantil, esta temática se articula como un componente más de denuncia social dentro del universo textual y adquiere especial protagonismo en una de las entregas de la saga Belascoarán Shayne. Concretamente en la sexta: Amorosos fantasmas.

La más breve de todas las que componen este proyecto narrativo policíaco, esta novela se publicó tras Días de combate (1976), Cosa fácil (1977), No habrá final feliz (1981), Algunas nubes (1985) y Regreso a la misma ciudad y bajo la lluvia (1989), y fue la última de las cuatro que han sido objeto de adaptación cinematográfica ${ }^{1}$. Publicada por Promexa en 1989, está escrita sobre la base de tres de los temas más reconocibles de

\footnotetext{
${ }^{1}$ Su estreno tuvo lugar en 1994 bajo la dirección de Carlos García Agraz y con Sergio Goyri en el papel protagonista. En total, cuatro novelas de la serie Belascoarán Shayne (Días de combate, Cosa fácil y Algunas nubes, además de esta) han sido adaptadas al cine, todas ellas producciones autóctonas y con cinco nominaciones a los premios Ariel, los más importantes de la cinematografía mexicana. Estos hechos nos hablan de la gran popularidad y difusión alcanzada por la saga en el país latinoamericano, sobre todo, en las décadas de los ochenta y noventa.
} 
la narrativa policíaca de Paco Ignacio Taibo II: en primer lugar, la reivindicación de la idiosincrasia mexicana -con especial mención a las singularidades culturales del país más a pie de calle (como la lucha libre, las rancheras, los boleros o las telenovelas)-; en segundo, la corrupción ejercida impune y verticalmente, en esta ocasión, bajo la forma de la trata de personas y con el fenómeno de captación de esclavas sexuales a manos de jóvenes sin recursos, también conocidos como "padrotes", como telón de fondo; por último, las sensaciones de desencanto y frustración que, evocadas casi a cada página, reproducen una poética de la derrota que impregna toda la novela desde su comienzo hasta las desoladoras palabras con las que termina: "Se quedó pensando en que, de nuevo, todos habíamos perdido otra batalla" (Taibo II, 2005: 229).

En el plano diegético, son dos las historias que relata la novela entrelazadas por el concepto universal del desamor y con el fracaso, como no podía ser de otra manera, como vaso comunicante entre ambas. En la primera, Héctor tiene que descubrir la identidad del asesino de su amigo y luchador enmascarado El Ángel (el mismo que, en Algunas nubes ayuda al detective a proteger a Ana junto con otro púgil, El Horrores, mientras se resuelve su caso de extorsión). Tras ser hallado su cuerpo sin vida en mitad del cuadrilátero sobre el que entrenaba, Belascoarán indagará en las claves de su muerte, rastreando su entorno más cercano con la ayuda de su hijo, el también luchador profesional Ángel II. Así descubre una vieja historia de amor entre El Ángel y Celia, una amiga y admiradora de la época en la que formaba pareja profesional con Zamudio, otro luchador amigo de ambos, bajo el nombre artístico de "Los fantasmas". Tras mantener una relación sentimental con Celia, de la que nacería una niña llamada Celina, el triángulo se rompe. Zamudio se separa de El Ángel y se marcha fuera del Distrito Federal en una huida supuestamente causada por los celos y la envidia al no poder ver correspondido su amor hacia Celia. Sin embargo, el final de la novela nos sorprende con un giro argumental inesperado. La investigación de Héctor desvela que Zamudio regresa veinte años después al D.F. para asesinar a El Ángel no por los celos, sino por el despecho, ya que el desenlace de la trama deja entrever una relación homosexual entre ambos.

El mismo amour fou, en su vertiente más desaforada, protagoniza la segunda trama, aunque, esta vez, como pretexto. Laura, una amiga de Héctor que trabaja como locutora de radio, pone al detective al corriente de lo que, a primera vista, parece responder a un suicidio en pareja de dos adolescentes, Virginia y Manuel, cuyos cuerpos sin vida son hallados en un apartamento a las afueras de la ciudad capitalina. Partícipes de un amor imposible, los dos habrían quedado para completar el acto fatídico después de grabar un mensaje de despedida con la idea de hacerlo llegar al programa de Laura, un espacio nocturno de radio dedicado a la música y a las llamadas en directo. Tras recibir en la emisora el mensaje, esta consigue convencer a los productores para que contraten a Belascoarán ante la sospecha de que todo es un montaje que puede esconder motivaciones más controvertidas. De esta manera, Héctor emprende una investigación que lo lleva a confirmar las conjeturas de Laura: en realidad 
se trata de una coartada. Virginia habría sido víctima de un intento de inducción a la prostitución a manos de Manuel, quien, a su vez, trabajaría como gancho para una organización dedicada a la trata de menores en el Distrito Federal, y cuyo cabecilla sería un poderoso industrial con importantes contactos en el mundo de la administración local llamado Márquez. Al lograr escapar de las redes de prostitución del entramado, y tras haber amenazado a Manuel con revelarlo todo a las autoridades, Márquez decide asesinarlos pretendiendo hacer pasar su muerte por un suicidio ante los medios de comunicación y la opinión pública.

\subsection{El personaje de Laura}

Aunque se observa de manera más clara en el caso de Virginia, tanto esta como Laura poseen dentro del relato una entidad de víctimas. Su condición de mujer las hace todavía más vulnerables si cabe en un entorno ya de por sí notablemente subyugador, dominado por la sinrazón y el dominio del más fuerte.

Por lo que respecta a su construcción como personajes, Laura reemplaza en la saga al del Cuervo Valdivia, otro personaje que aparece en Cosa fácil y No habrá final feliz, al frente del programa de radio La hora de los solitarios. Este programa se instituye dentro del universo ficcional taibodiano como una herramienta más al servicio de la concienciación ciudadana y la denuncia solidaria entre los miembros más expuestos a la violencia generada por el sistema bajo el imperio del PRI. Además de como víctima, Laura cumple en la novela con las funciones de donante y ayudante ocasional en la investigación sobre la muerte de Virginia (Propp, 1981: 91). Responde como personaje al perfil de periodista de moral íntegra e independiente tan reivindicado por Taibo II. En continuo conflicto con el entorno que le rodea por tanto, su caracterización, sin embargo, carece de mayor calado y responde a la de un personaje plano. Para su caracterización, la instancia narrativa recurre a dos arquetipos del mundo del espectáculo. En primer lugar, del cine:

- Se imaginó [Héctor] a Laura: auriculares puestos, [...] frente al micro. Como el retrato de una de aquellas intelectuales que dibujaba [...] Hollywood [...] que cuando se deshacían el rodete en que llevaban recogido el pelo se transmutaban en vampiresas desmelenadas y de labios carnosos (Taibo II, 2005: 150).

Y, en segundo lugar, de la televisión:

Laura no traía los lentes que le daban su habitual cobertura intelectual y, por lo tanto, más bien lucía como una modelo yanqui de anuncio de Miss Clairol, la cabellera sacudiéndose al vaivén de la carrera (Taibo II, 2005: 159).

Con ellos, concreta una caracterización física cargada de erotismo y sensualidad. 
Personaje, por tanto, de menor entidad, parece ser utilizado por el autor, por un lado, para cumplir con las funciones literarias comentadas $y$, por otro, como pretexto para introducir en el relato parte del contenido de denuncia social sobre nociones como inseguridad ciudadana y violencia. Asociadas al entorno urbano en el que se desarrolla la acción, la Ciudad de México, su capacidad nociva para comprometer la integridad física y psicológica de los personajes es tan potente que es equiparada por el narrador al efecto del tabaco o el alcohol. Así lo revela el siguiente extracto. Con el humor negro que caracteriza muchas de las aventuras de la saga impulsando la denuncia contra la inseguridad, el detective pone en evidencia, con la alusión a la violación como telón de fondo, la incongruencia por parte de Laura de intentar practicar ejercicio para mantenerse en forma en una ciudad como el Distrito Federal:

- En teoría deberían ser diez vueltas, pero como te tengo aquí lo voy a dejar en ocho -dijo Laura jadeando, y se dejó caer al pie de la banca.

- Solo tú te crees eso de que me vas a hacer el favor. Estás al borde del infarto. Fumas más que yo, vives en el DF, bebes cerveza Tecate como si fuera jugo de manzana y luego quieres ser sana. Lo único sensato de dar ocho vueltas es que ningún violador se animaría; en general son una punta de güevones, les gustan las de tres vueltas nada más (Taibo II, 2005: 161).

\subsection{El personaje de Virginia}

Toda esta violencia contra la mujer intuida en el personaje de Laura, termina por materializarse en el caso de Virginia. A pesar de costarle la vida, ni para ella, ni para su familia -las otras víctimas de la novela- hay reparación ni justicia. Toda la sinrazón del sistema cae sobre ella al verse envuelta sin quererlo en un juego de intereses cruzados e intentar denunciarlo. Tanto el tratamiento, como su caracterización en la novela -a través de pasajes en los que se alternan la mediación del narrador (heterocaracterización) y sus propias grabaciones (autocaracterización) - desprenden ternura, afecto y rabia. Sobre todo, en lo relativo a su retrato físico, donde el narrador no duda en suspender el tiempo de la diégesis por medio de la cámara lenta (Genette, 1989: 117), como demuestra la siguiente descripción de su cuerpo exangüe con la que se nos introduce al personaje, persiguiendo impactar y sensibilizar al receptor del texto una vez más:

Sobre la cama había una muchacha tendida, cubierta por una sábana, solo libres la cabeza y el cuello; a la altura del corazón, una mancha de sangre. La sábana parecía haber sido puesta después de la muerte sobre el cuerpo desnudo. Era un rostro muy bello al que la ausencia de la vida, la palidez, no le quitaban el gesto de tranquilidad e inocencia. Una mezcla de la novia que nunca pudimos tener en la prepa y la hija del 
vecino, que si nos hubiéramos casado a tiempo podría ser hija nuestra y nosotros contemplarla dormir deseándole la mejor de las suertes, los mejores amores, la mejores batallas (Taibo II, 2005: 155-156).

En el ámbito psicológico, su caracterización responde más al patrón de adolescente idealista, con la representación de una personalidad contradictoria y en pleno proceso de formación. En ella tienen cabida todo un muestrario de pensamientos, frustraciones, miedos e inquietudes propias de esta edad, donde se entretejen la congoja provocada por el acné con la valentía heroica de plantarle cara al sistema pretendiendo denunciar la trama de prostitución de menores orquestada por Manuel y su tío, el industrial Márquez:

Ésta es la tercera vez que Virginia me mandaba una
cinta al programa [... contaba cosas como
manifestaciones del CEU [sindicato estudiantil
independiente de la UNAM] mezcladas con
angustiosas peticiones para eliminar el acné,
descripciones de los leones haciendo el amor en el
zoológico mezcladas con lecturas de los sonetos de
amor de Shakespeare (Taibo II 2005: 162).

2. Mujer y violencia en Amorosos fantasmas: un acercamiento a la figura del padrote y la prostitución de menores en el contexto mexicano

También el plano de la denuncia social, la novela carga de manera clara a lo largo de sus páginas contra otro sistema de dominación entre personas muy arraigado y con una gran presencia dentro del campo de las dinámicas sociales del país latinoamericano: la trata de personas a través de organizaciones criminales dedicadas a la explotación sexual de mujeres, principalmente menores. Fenómeno con una gran presencia en estados como Txalcala, Puebla, Veracruz, el Estado de México o el propio Distrito Federal, tiene como actores axiales al "padrote" y a la mujer menor de edad susceptible de prostitución. Asimismo, no se puede entrar a abordar la naturaleza e implicaciones de este fenómeno social sin poner de manifiesto, una vez más, las condiciones de vulnerabilidad familiar, social, cultural, emocional, económica y, como no, educativa que, resultantes de la desatención e incompetencia del Estado Mexicano, conforman el escenario sobre el que se asienta esta práctica de sumisión femenina con la desigualdad, y la precariedad económica como comunes denominadores (Yglesias, 2014).

Los orígenes de la explotación sexual en México se remontan a tiempos coloniales. Sin embargo, experimenta un importante proceso de desarrollo coincidiendo con contextos históricos de agitación social y política -como el de la Independencia (1810-1821), la Reforma (18571861) o la Revolución (1910-1920) - durante el siglo XIX y el primer tercio del XX. De esta manera, se prolonga hasta nuestros días, tras alcanzar cotas muy significativas entre las décadas de los cincuenta y los ochenta, 
en un contexto originariamente rural, aunque posteriormente extendido a los núcleos urbanos (Martínez, 2013: 58).

Como apunta el sociólogo e historiador Óscar Montiel, dentro del campo del comercio sexual en México, uno de los elementos más importantes es el del agente que sirve de intermediario para satisfacer la demanda de mujeres. Conocido generalmente como "padrote", es el protagonista de una práctica que, producto de un hábito adquirido dentro del comercio sexual femenino con fines de explotación, requiere de un sentido práctico para reclutar mujeres. A través de este, el padrote trata de convencerlas, generalmente por medio de la seducción y el engaño, para trabajar como prostitutas, haciendo, en última instancia, que conciban su cuerpo como una mercancía (Montiel, 2009: 160). Sus ámbitos de actuación, como muy bien refleja la novela son dos. Por un lado, las casas de citas: un espacio tanto geográfico como social y simbólico donde los varones enseñan y aprenden los mecanismos de poder y las herramientas dialécticas de persuasión del padrote. En la novela sería la casa en el barrio acomodado de las Lomas de Chapultepec donde vive Márquez:

El paisaje comenzó a poblarse de ciudadanos en calzoncillos. Sus viejos amigos, los dos guaruras correlonas, aparecieron por una puerta de servicio en un costado del edificio. [...] En un pasillo del piso superior se cruzó con dos niñas de no más de 12 años en camisón. (Taibo II, 2005: 215)

Por otro, la calle, en especial localizaciones donde pueden acechar mejor a sus víctimas como las entradas de los colegios, a los que acuden con coches de primera marca para ofrecerse a llevarlas a casa:

- ¿Y conoció usted al novio, el que murió con ellas? No era el novio, era un chavito que le estaba echando los perros, pero ella no le hacía mucho caso. [...] Una vez le quiso dar un aventón a la señorita, venía con su papá, y ella los mandó a la chingada (Taibo II, 2005: 171).

La precisión con la que Taibo II retrata este fenómeno la demuestra la utilización de frases hechas o expresiones propias de la jerga de los padrotes como "echar los perros" o "dar un aventón". La primera tendría como primera acepción la de mostrar una actitud amenazante contra alguien y como segunda la de tratar de seducir y conquistar, insinuando un interés sexual o romántico. La segunda significaría ofrecerse para trasladar con un coche a otra persona (Gómez de Silva, 2001: 252).

El retrato crítico que hace el autor de este fenómeno acierta también al abordarlo no como una sucesión de actos de seducción y proxenetismo aislados, sino como un negocio controlado por entramados $\mathrm{u}$ organizaciones complejas integradas por varios actores con funciones perfectamente delimitadas. $Y$ es que los padrotes no son los únicos actores de este entramado. Según Ixchel Yglesias González, a estos 
habría que sumar desde los comerciantes que venden productos de aseo personal (ropa, profilácticos o maquillajes) o los conocidos "guaruras" (personas dedicadas a la seguridad de los centros donde se ejerce esta actividad), a los dueños de estos locales clandestinos. También a los clientes y a los estamentos político y policial que los mantienen, bien a través del consumo, bien por medio de la inacción (Yglesias, 2014):

- En vez de andar regalándome un cheque, por qué no
me cuenta el lugar que ocupaba su sobrino en la
organización que usted tiene... O qué fue lo que
averiguó Virginia Vali que a usted tanto le molestaba...
[...].

Márquez se rió.

- Usted tiene muchas preguntas, demasiadas, amigo. Pregunta más que la policía. Mis amigos de la policía no andan encendiendo cheques como usted, nomás los cobran (Taibo II, 2005: 212).

Por último, Taibo II se hace eco a través del personaje de Manuel de las técnicas más relevantes para la pedagogía de la explotación. Según la categorización del oficio de padrote que hace José Manuel Martínez Aguilar, este respondería al modelo de traficante por tradición familiar, ya que su labor no tiene como objeto captar a sus propias trabajadoras sexuales, sino abastecer de sexoservidoras a negocios especializados como el que dirige su tío Márquez. Sus estrategias de dominación incluyen la de "ser bien verbo" o tener el don de la elocuencia, matar todo atisbo de sentimiento para con la víctima, conseguir que la mujer conciba su cuerpo como mercancía y no dejar que esta imponga en ningún momento su forma de pensar (Martínez, 2013: 97-98). Todas estas son herramientas perfectamente integradas en la conducta del personaje y que, con el paso del tiempo, conducen a la despersonalización o deshumanización de la víctima: fase final del proceso de explotación que, siguiendo a Tzvetan Todorov, termina por convertirlas en piezas de un sistema de dominación que las trasciende a fuerza de acabar olvidando su condición como ser humano. La despersonalización puede golpear igualmente sobre uno mismo o sobre otro. A fuerza de considerar al otro como simple elemento de un proyecto que le trasciende, se acaba por olvidar que es un ser humano; pero a fuerza de someterse uno mismo a las exigencias del sistema, uno se transforma en pieza de máquina. Bestia o máquina, de ambas maneras se pierde la condición humana, en palabras del filósofo búlgaro (Todorov, 1993: 207). No es de extrañar por tanto que, hacia el final de la novela, Taibo II aluda a esta última etapa del procedimiento de esclavización de la víctima a través del siguiente pasaje en el que, por un lado, la búsqueda obsesiva de una fotografía de Virginia en la casa de Márquez, y, por otro, el olvido de su nombre se constituyen como dos instantes de gran carga simbólica. De ellos se sirve el autor para tematizar esta fase crucial del proceso de deshumanización en el que la víctima ha sido despojada ya de su condición e identidad como persona. Un momento clave en el que la 
labor del "padrote" ha calado por completo y la víctima se encuentra en un estadio de sumisión difícilmente reversible y prácticamente irreparable desde el punto de vista social:

\begin{abstract}
¿Qué buscaba? Una foto. ¿Por qué? Porque aquí tendría que haber también una foto. La descubrió en una recámara de alfombras rojas. Estaba sobre la mesita de noche, era otra vez el rostro de Virginia, la adolescente muerta, que no lo parecía en la foto. [...] Márquez estaba vestido tan solo con un pijama, [...] Caminó hacia la foto pasando al lado de Héctor y la tomó entre las manos.
\end{abstract}

-Tengo debilidad por las muchachas muy jóvenes, son tan suaves. [...] ¿Cómo se llamaba la escuincla pendeja esta? (Taibo II, 2005: 215).

\title{
3. Conclusión
}

A la vista de lo referido en este artículo de investigación, se puede concluir que tanto la mujer como toda la problemática relacionada con su mayor vulnerabilidad ante la violencia y la inseguridad ciudadana, así como la explotación sexual de la que es también objeto, aparecen como objeto de reflexión en la narrativa policíaca del escritor mexicano Paco Ignacio Taibo II, más concretamente, en la saga literaria protagonizada por el detective Belascoarán Shayne.

Escrita bajo la premisa de catapultar una acerada denuncia contra los desmanes del régimen priísta desde finales de la década de los setenta a comienzos de los noventa, en el año 1989 aparece su sexta entrega, la novela Amorosos fantasmas, con el objetivo de llamar la atención sobre lacras sociales como, por un lado, la violación y el feminicidio -a través de los personajes femeninos de la novela-, y, por otro, el fenómeno de la prostitución de menores ligado a la figura del padrote. Una práctica delictiva con mucho arraigo social en el país azteca y que Taibo II retrata en toda su complejidad. No como un fenómeno aislado, sino, por un lado, como organizaciones bien estructuradas resultantes de la injusticia social -derivada de la podredumbre moral y la corrupción del orden sistémico tanto a nivel social, como a nivel político y económico- y, por otro lado, como una forma también de dominación que le acarrea un inevitable proceso de anulación identitaria a la mujer que es víctima de él.

\section{Referencias bibliográficas}

GENETTE, Gérard. Figuras III. Barcelona: Lumen, 1989.

GómEZ DE SILVA, Guido. Diccionario breve de mexicanismos. Ciudad de México: Academia Mexicana-F.C.E, 2001.

MARTínez AgUILAR, José Manuel. La trata de personas en el siglo XXI, sus repercusiones sociales. Un estudio de caso. Ciudad de México: Servicio de Publicaciones de la UNAM, 2013. 
MONTIEL TORRES, Óscar. Trata de personas. Padrotes, iniciación y modus operandi. Ciudad de México: Instituto Nacional de las Mujeres, 2009.

NichOLS, William. "A quemarropa con Manuel Vázquez Montalbán y Paco Ignacio Taibo II". Arizona Journal of Hispanic Cultural Studies 2, no. 1 (1998): 197-231.

PROPP, Vladímir. Morfología del cuento. Madrid: Fundamentos, 1981.

STRADA, Mauricio. "El periodismo heroico, conversación con Paco Ignacio Taibo II". Neotipi. Consultado el 23 de marzo de 2017. http://www.vespito.net/taibo/esp/scrit.html.

TAIBo II, Paco Ignacio. 68. Ciudad de México: Joaquín Mortiz, 1991.

TAIBO II, Paco Ignacio. Primavera pospuesta: una versión personal de México en los 90. Ciudad de México: Joaquín Mortiz, 1999.

TAIBO II, Paco Ignacio. Amorosos fantasmas. Barcelona: Planeta, 2005.

Todorov, Tzvetan. Frente al límite. Ciudad de México: Siglo XXI, 1993.

TORRES, Vicente Francisco. Muertos de papel: un paseo por la narrativa policial mexicana. Ciudad de México: Sello Bermejo, 2003.

YGLESIAS GONZÁLEZ, Ixchel. "El sistema proxeneta y las espirales de violencia y subordinación femenina en contextos de prostitución". Actas del Youth Symposium Endslavery. Consultado el 24 de febrero de 2018. http://www.endslavery.va/content/endslavery/es/publications/youth symp osium 2014/proxenetas.pdf. 
Ambigua, Revista de Investigaciones sobre Género y Estudios

Culturales, n. ${ }^{\circ}$ 7, 2020, pp. 198-210. ISSN: 2386-8708 